\title{
Ethnic and Gender Differences in Help Seeking for Substance Disorders Among Black Americans
}

\author{
Michelle L. Redmond ${ }^{1}$ • Daphne C. Watkins ${ }^{2}$ • Clifford L. Broman ${ }^{3} \cdot$ Jamie M. Abelson $^{2}$ • \\ Harold W. Neighbors ${ }^{2}$
}

Received: 19 October 2015 / Revised: 22 February 2016/Accepted: 28 March 2016 /Published online: 28 April 2016

(C) W. Montague Cobb-NMA Health Institute 2016

\begin{abstract}
This paper uses the National Survey of American Life (NSAL) to examine within group differences regarding help-seeking for substance disorders among a US sample of African American and Caribbean Black men and women. We examined ethnic and gender differences in the type of providers sought for substance disorder treatment, as well as reasons for avoiding treatment. Results indicate that overall, few ethnic differences exist; however, African Americans are more likely than Caribbean Blacks to seek help from human service professionals (including a religious or spiritual advisor) and from informal sources of treatment such as self-help groups. Black men with a substance disorder were more likely to see a psychiatrist than Black women. Findings regarding reasons for avoiding treatment suggest that there may be a need to provide better education about the utility of substance disorder treatment, even before problems reach a high level of severity.
\end{abstract}

Keywords Help-seeking · African American · Caribbean black $\cdot$ Substance use $\cdot$ Barriers $\cdot$ Health disparities

Evidence from the National Comorbidity Survey Replication suggests that many people who are in need of substance

Michelle L. Redmond

mredmond@kumc.edu

1 University of Kansas School of Medicine-Wichita, 1010 N. Kansas, Wichita, KS 67214, USA

2 University of Michigan, Ann Arbor, MI, USA

3 Michigan State University, East Lansing, MI, USA disorder treatment do not seek help [1,2]. As noted in results from the National Survey on Drug Use and Health [NSDUH], 23 million people are in need of specialty substance use treatment, while only 2.5 million actually receive services, indicating a substantial unmet need for substance disorder treatment [3]. Epidemiological studies indicate overall, among those with substance disorder issues, African Americans are underserved, and obtain treatment less often than Whites [3-5]. Blacks as a group have a lower prevalence of drug and alcohol use, but among those who do have substance issues, there is a high need for treatment [6]. It is estimated that $9.1 \%$ of Black Americans are in need of treatment for substance disorders [6]. Included in that number are $4.1 \%$ who are in need of treatment for illicit drug use, which is significantly higher than the national average of $3.0 \%$ [6]. Black Americans (specifically African Americans and Caribbean Blacks) experience significant challenges in accessing and receiving substance disorder (alcohol and other drug abuse and dependence) treatment. For example, Black Americans delay seeking treatment, have shorter treatment durations, and experience significant social and health-related consequences because of their substance use, compared to White Americans [7-10]. For many Black adults, these consequences include poverty, unemployment, lack of a high school diploma or GED, health aliments, and drug-related legal problems [11-13]. More than other racial/ethnic groups, Black adults tend to have longer "careers" with drug and alcohol abuse [13] and tend to seek help once their problems reach a heightened level of severity [14]. This delay complicates treatment. When individuals enter substance use treatment with greater severity, they also have greater chronic health and social issues that need to be addressed during the treatment process, in addition to treating their substance disorder [15]. Preventive measures, as well as those that ease entry into treatment, are needed to reach this population of substance users. In order to improve overall 
treatment access and completion, it is important to understand ethnic and gender help-seeking variation among Black Americans. This paper seeks to understand variations in the type of provider sought for substance disorder treatment and reasons for delaying the treatment process among Black Americans.

\section{Help-Seeking Practices}

Substance use help-seeking practices among Black Americans are generally compared against help-seeking practices of White Americans. While this is useful, it is also important to understand the dynamics that exist within ethnic groups [16]. Only limiting comparisons to Black and White Americans does not allow researchers to look specifically at the variability, trends, and correlates of help-seeking patterns that exist within the Black population. There is considerable within group heterogeneity that might contribute to help-seeking patterns and practices. Heterogeneity includes ethnic variation, (native African American, Caribbean Black, Spanish, and African), regional differences, immigrant status, and cultural differences. Understanding ethnic variation can help improve the process of identifying treatment needs and has ramifications when planning treatment referral and preventive strategies to reduce the level of unmet need [15].

\section{Reasons for Delaying Treatment}

Literature about race differences shows that Black adults in need of substance use treatment tend to delay treatment until problems are most severe, are in treatment for a shorter duration of time, and have less perceived need for help [3, 16-19]. It is unclear what ethnic variations exist, or which characteristics are most important among those Black Americans who perceive no need for treatment, or who delay treatment. Perron and colleagues found Blacks cited internal barriers most often for delaying substance disorder treatment [20]. Those who delayed treatment thought they were strong enough to handle their substance disorder problem alone, or thought their problem would eventually get better without treatment [20]. Again, we do not know the ethnic variation in why these Black respondents delayed treatment. This could have implications for the type of treatment needed and strategies used by practitioners to retain reluctant clients.

\section{Ethnic Variation in Help-Seeking for Substance Use Treatment}

While knowledge of ethnic variations during participation in substance disorder treatment and avoidance of treatment is limited, some studies have provided valuable findings on emerging patterns of Black ethnic variation in mental health help seeking process. Jackson and colleagues found no ethnic variation in general mental health help seeking among African Americans and Caribbean Blacks [21]. However, among Caribbean Blacks, they did find that those who immigrated to the USA at an earlier age reported more service use, as did Caribbean Blacks from Spanish speaking countries. Neighbors and colleagues also found no ethnic variation in specialty mental health help seeking [22]. They did find that younger and older Black Americans sought help less often than those in a middle age group (ages 30-59) did. Woodward and colleagues also found ethnicity was not related to help seeking. For substance use help seeking, Woodward and colleagues also reported that Black Americans who met criteria for a substance use disorder sought help less often than those with a mental health disorder did, which is similar to findings among other racial/ethnic groups [13]. In addition, Black adults with high problem severity sought more help than those with low problem severity and male respondents were less likely to seek treatment than female respondents [13]. In another study, Woodward and colleagues found African American males relied more often on informal support alone compared to Black Caribbean men for mental disorder treatment [23]. Understanding the nuances of ethnic variation in help seeking is important in meeting the treatment needs of Black Americans. Thus, more studies are needed to understand the characteristics of help seeking within this group.

Despite the increasing literature on Black Americans help-seeking practices, studies on ethnic variation of help-seeking practices among Black adults are limited. A significant majority of substance disorder help-seeking studies currently focus solely on African Americans. The purpose of this study was to investigate Black ethnic and gender differences in help-seeking practices, as well as reasons for avoiding treatment. We want to determine are there differences in the type of service provider sought for treatment among Black adults? Understanding the type of service provider sought can help shed light on how to intervene, how Black Americans are referred for treatment or where they are not referred, and the type of providers that are most commonly sought. In order to achieve the aims of this study, first, we examined differences in service provider use by ethnicity and gender. Then, we examined correlations among gender, ethnicity, age, insurance, and education in predicting the type of service provider sought. Lastly, we examined the reasons for avoiding treatment by looking at ethnic and gender differences. 


\section{Method}

\section{Sample}

The National Survey of American Life (NSAL) is a comprehensive study of the mental health of Black Americans [24]. The study, conducted between February 2001 and June 2003, is part of an NIMH Collaborative Psychiatric Epidemiology Surveys (CPES) initiative [25]. The NSAL adult sample is an integrated national household probability sample of 3570 African Americans, 1621 Blacks of Caribbean descent (Caribbean Blacks), and 891 non-Hispanic whites living in areas where at least $10 \%$ of the population is black, all aged 18 and over [26]. In both the African American and Caribbean black samples, it was necessary for respondents to selfidentify as black. Those self-identifying as black were included in the Caribbean Black sample if they answered affirmatively when asked if they were of West Indian or Caribbean descent, or if they said they were from a country included on a list of Caribbean area countries provided by the interviewers. Most interviews were conducted face-to-face using a computer-assisted instrument and lasted an average of $2 \mathrm{~h}$ and $20 \mathrm{~min}$. The final overall response rate was $72.3 \%$, with $70.7 \%$ for the African American sample, $77.7 \%$ for Caribbean Blacks, and $67.7 \%$ for the non-Hispanic white sample. Due to time and budget constraints, NSAL white respondents were not asked the substance use questions. The focus of this paper is on the two Black ethnic samples. This study was approved by the University of Michigan Institutional Review Board.

\section{Measures}

Sociodemographic Correlates Sociodemographic correlates include ethnicity (African American, Caribbean Black), age (a continuous variable ranging from 18 to 94), sex (dummy coded, where $1=$ male), and years of education completed (a continuous variable ranging from 4 to 17 years). We also control for insurance status. This measure is dummy coded where $1=$ the respondent has insurance.

Diagnostic Assessment The Diagnostic and Statistical Manual (DSM-IV) World Mental Health Composite International Diagnostic Interview (WMH-CIDI), a fully structured diagnostic interview, was used to assess a wide range of mental disorders. The mental disorder sections used for the NSAL, including substance use, are slightly modified versions of those developed for the World Mental Health project initiated in 2000 [27] and the instrument used in the National Comorbidity Survey Replication (NCS-R) [28-29]. The substance disorders included in these analyses are alcohol abuse, alcohol dependence (with abuse), drug abuse, and drug dependence (with abuse). A question item oversight led to respondents being exempt from completing the dependence section if they did not meet criteria for abuse - a concern since DSM-IV criteria do not require abuse to meet dependence. As a result, respondents with alcohol dependence or drug dependence who did not also have alcohol abuse or drug abuse are missing. Therefore, the number of respondents with alcohol or drug dependence is smaller than it should be. Most people with alcohol dependence or drug dependence also have alcohol or drug abuse, so we do not believe that the number of people missing is substantial.

\section{Dependent Variables}

Our dependent variables were service providers and reasons for avoiding substance use treatment. Help-seeking was assessed by determining the type of service provider respondents utilized for treatment of their substance use problems. There were six types of service providers examined: psychiatrists, other mental health professionals (psychologist, psychotherapist, social worker, a mental health nurse, or counselor), general medical doctor (family doctor, any medical doctors other than a psychiatrist), other health professionals (nurse, physician's assistant), human service professionals (including religious or spiritual advisors), and informal sources of treatment (self-help groups, alternative medicine). Reasons for avoiding treatment were assessed for those who answered in the affirmative that they never sought treatment for a substance use problem in the past 12 months or during their lifetime. People who answered "no" to seeking help were asked whether 13 reasons for not seeking help pertained to them, additionally being allowed to give their own reasons for not seeking help. Responses were coded as follows: "thought problem would get better," "felt better," "didn't bother me," "wanted to solve on my own," "didn't think [treatment] would help," "could not afford [treatment]," "worried what others would think," "inconvenient," "didn't know where to go," "embarrassed," "talked to a friend," "don't know," and "other reasons."

\section{Analysis Procedure}

Cross-tabulations present ethnic differences in the prevalence of lifetime substance disorders. Odds ratios and $95 \%$ confidence intervals from logistic regression models were used to assess associations between indicators of age, education, gender, and ethnicity and the use of professional help. Data used in these analyses are weighted to correct for unequal probabilities of selection, non-response, and for population representation across various sociodemographic characteristics. All analyses were conducted using Stata 9, because it is capable of handling complex survey data such as the NSAL [30]. 


\section{Results}

The analyses were restricted to respondents who meet criteria for a DSM-IV substance disorder (alcohol or drug abuse or dependence (with abuse). Of those who meet DSM-IV criteria $(n=472), 240$ indicated that they had sought services from a service provider for substance disorder problems either in the past 12 months or sometime during their lifetime. Of the 240 respondents who sought services for a substance disorder problem during their lifetime, 140 were female and 100 were male. As for differences by ethnicity, 195 were African American and 45 were Caribbean Black. Overall, among those who sought help, African Americans most commonly sought help from "other health professionals" (81\%), and from self-help groups or other informal sources of care $(75.9 \%)$. Caribbean Blacks also sought help more often from "other health professionals" $(86.7 \%)$, followed by mental health professionals (62.2\%). African American (32.3\%) and Caribbean Black $(33.3 \%)$ respondents were least likely to seek help from a psychiatrist (Table 1).

There were no statistically significant differences between African Americans and Caribbean Blacks in terms of seeking services from a psychiatrist, other mental health professional, or from another medical doctor for substance disorder problems. However, differences did exist between these two groups when seeking services from a human service provider (including a religious/spiritual advisor) or from informal sources of treatment (self-help group, alternative healers). African Americans were more likely to utilize services from a human service provider (including religious or spiritual advisors) and seek help from selfhelp groups compared to Caribbean Blacks. Gender differences did exist when predicting service use for a psychiatrist. Male respondents were more likely to seek help from a psychiatrist over the course of their lifetime compared to female respondents. There were no other gender differences in the use of other types of service providers (Table 1).

\section{Correlates of Help-Seeking by Age and Education}

In terms of sociodemographic correlates, age was a significant predictor for using services from a general medical doctor, other health professional and informal sources. Older respondents were more likely to seek substance use services from these three sectors. As age increased, respondents were more likely to use services from any service provider (Table 2). Level of education was a significant predictor of seeking help from other mental health professionals (psychologist, psychotherapist, social worker, mental health nurse, or counselor). Having more education was also a predictor of seeking help from a human service professional (including religious or spiritual advisors) or from an informal source of treatment.
Table 1 Help-seeking by profession: ethnicity and gender

\begin{tabular}{|c|c|c|c|c|c|c|c|c|c|}
\hline & & \multicolumn{2}{|c|}{$\begin{array}{l}\text { African } \\
\text { American }\end{array}$} & \multicolumn{2}{|c|}{$\begin{array}{l}\text { Caribbean } \\
\text { Blacks }\end{array}$} & \multicolumn{2}{|c|}{ Male } & \multicolumn{2}{|c|}{ Female } \\
\hline \multirow[t]{2}{*}{ Professional treatment } & & \multicolumn{2}{|c|}{$(n=195)^{\mathrm{c}}$} & \multicolumn{2}{|c|}{$(n=45)^{\mathrm{e}}$} & \multicolumn{2}{|c|}{$(n=100)^{\mathrm{g}}$} & \multicolumn{2}{|c|}{$(n=140)^{\mathrm{i}}$} \\
\hline & Total $N^{\mathrm{a}}$ & $n$ & $\%^{\mathrm{b}}$ & $n$ & $\%^{\mathrm{d}}$ & $n$ & $\%^{\mathrm{f}}$ & $n$ & $\%^{\mathrm{h}}$ \\
\hline Psychiatrist & 78 & 63 & 32.3 & 15 & 33.3 & 40 & 40 & 38 & 27.1 \\
\hline Mental health professional & 117 & 89 & 45.6 & 28 & 62.2 & 51 & 51 & 66 & 47.1 \\
\hline General medical doctor & 123 & 103 & 52.8 & 20 & 44.4 & 54 & 54 & 69 & 49.3 \\
\hline Health professional & 197 & 158 & 81 & 39 & 86.7 & 87 & 87 & 110 & 78.6 \\
\hline Human service professional & 79 & 71 & 36.4 & 8 & 17.7 & 36 & 36 & 43 & 30.7 \\
\hline Informal source of treatment & 172 & 148 & 75.9 & 24 & 53.3 & 68 & 68 & 104 & 74.3 \\
\hline
\end{tabular}

${ }^{a}$ Number of respondents for each type of service provider

${ }^{\mathrm{b}}$ Percentage of African Americans who sought help divided by total number of African Americans who sought help in their lifetime

${ }^{\mathrm{c}}$ Total number of African Americans who sought help during their lifetime

${ }^{\mathrm{d}}$ Percentage of Caribbean Blacks who sought help divided by total number of Caribbean Blacks who sought help in their lifetime

${ }^{\mathrm{e}}$ Total number of Caribbean Blacks who sought help during their lifetime

${ }^{\mathrm{f}}$ Percentage of males who sought help divided by total number of males who sought help in their lifetime

${ }^{\mathrm{g}}$ Total number of males who sought help during their lifetime

${ }^{\mathrm{h}}$ Percentage of females who sought help divided by total number of females who sought help in their lifetime

${ }^{\mathrm{i}}$ Total number of females who sought help during their lifetime 
Table 2 Odds ratio estimates with corresponding $95 \%$ confidence interval for use of service provider by sociodemographic characteristics: NSAL 2001-2003

\begin{tabular}{|c|c|c|c|c|c|c|c|c|c|c|c|c|c|c|}
\hline \multirow[b]{2}{*}{$\begin{array}{c}\text { Independent } \\
\text { variable }\end{array}$} & \multicolumn{2}{|c|}{ Psychiatrist } & \multicolumn{2}{|c|}{$\begin{array}{l}\text { Mental health } \\
\text { professional }\end{array}$} & \multicolumn{2}{|c|}{ General doctor } & \multicolumn{2}{|c|}{$\begin{array}{l}\text { Health } \\
\text { professional }\end{array}$} & \multicolumn{2}{|c|}{$\begin{array}{l}\text { Human service } \\
\text { professional }\end{array}$} & \multicolumn{2}{|c|}{$\begin{array}{l}\text { Informal source } \\
\text { of treatment }\end{array}$} & \multicolumn{2}{|c|}{$\begin{array}{l}\text { Any service } \\
\text { provider }\end{array}$} \\
\hline & $\begin{array}{l}\text { Odds } \\
\text { ratio }\end{array}$ & $95 \% \mathrm{CI}$ & $\begin{array}{l}\text { Odds } \\
\text { ratio }\end{array}$ & $95 \%$ CI & $\begin{array}{l}\text { Odds } \\
\text { ratio }\end{array}$ & $95 \% \mathrm{CI}$ & $\begin{array}{l}\text { Odds } \\
\text { ratio }\end{array}$ & $95 \% \mathrm{CI}$ & $\begin{array}{l}\text { Odds } \\
\text { ratio }\end{array}$ & $95 \% \mathrm{CI}$ & $\begin{array}{l}\text { Odds } \\
\text { ratio }\end{array}$ & $95 \% \mathrm{CI}$ & $\begin{array}{l}\text { Odds } \\
\text { ratio }\end{array}$ & $95 \% \mathrm{CI}$ \\
\hline Age & 1.01 & $.980-1.02$ & 1.01 & $.998-1.03$ & $1.02 *$ & $1.01-1.04$ & $1.02 *$ & $1.00-1.03$ & 1.00 & $.984-1.02$ & $1.02 *$ & $1.00-1.04$ & $1.01^{*}$ & $1.00-1.03$ \\
\hline \multicolumn{15}{|l|}{ Gender } \\
\hline Male & $0.55^{*}$ & $.336-.902$ & 0.75 & $.493-1.17$ & 0.71 & $.464-1.09$ & 0.69 & $.469-1.00$ & 0.72 & $.442-1.19$ & 0.918 & $0.62-1.36$ & 0.79 & $.548-1.16$ \\
\hline Female & Ref & & Ref & & Ref & & Ref & & Ref & & Ref & & Ref & \\
\hline Education & 1.02 & $.670-2.15$ & $1.12 *$ & $1.02-1.24$ & 1.04 & $.949-1.15$ & 1.09 & $.998-1.19$ & $1.13^{*}$ & $1.00-1.26$ & $1.10^{*}$ & $1.00-1.20$ & 1.08 & $.993-1.18$ \\
\hline \multicolumn{15}{|l|}{ Ethnicity } \\
\hline $\begin{array}{l}\text { African } \\
\text { American }\end{array}$ & 1.0 & $.526-1.80$ & 0.75 & $.442-1.28$ & 1.30 & $.736-2.30$ & 0.97 & $.599-1.58$ & $2.77^{*}$ & $1.25-6.14$ & $1.90 *$ & $1.11-3.24$ & 1.09 & $.674-1.76$ \\
\hline $\begin{array}{l}\text { Carribean } \\
\text { Black }\end{array}$ & Ref & & Ref & & Ref & & Ref & & Ref & & Ref & & Ref & \\
\hline \multicolumn{15}{|l|}{ Insurance } \\
\hline Yes & 1.10 & $0.67-2.15$ & 0.99 & $.593-1.58$ & 1.13 & $.696-1.85$ & 1.07 & 699-1.64 & 0.973 & $.556-1.70$ & 0.945 & $.609-1.47$ & 1.05 & $.688-1.59$ \\
\hline No & Ref & & Ref & & Ref & & Ref & & Ref & & Ref & & Ref & \\
\hline
\end{tabular}

Adjusted for age, gender, educational level, insurance, and ethnicity

*Significant at $p<.05$

\section{Correlates of Help-Seeking by Ethnicity and Gender}

We assessed ethnic variation in the type of professional utilized by respondents and found no significant differences in use of a psychiatrist, other mental health professional, or any other medical doctor. However, African American respondents were more likely to utilize human service providers, including religious or spiritual advisors $(p<.05)$ and selfhelp groups or other informal sources of help $(p<.05)$, compared to Caribbean Blacks (Table 2). In measuring associations between gender and type of service provider, we found that gender was a significant predictor for seeking help from a psychiatrist. Males were more likely to utilize services from a psychiatrist compared to female respondents. Gender was not a significant predictor for obtaining help from the remaining types of treatment professionals.

\section{Reasons for Avoiding Treatment}

Respondents who met DSM-IV criteria for a substance disorder problem, but did not seek help, gave several reasons for avoiding treatment (Table 3). Overall, most respondents indicated they did not seek help because they felt their substance use problem was not serious enough ( $23 \%)$, they thought the problem would get better on its own $(22 \%)$, or they did not need or think they needed help (12.5\%). When we examined variations by ethnicity, we found no statistically significant differences between African Americans and Caribbean Blacks in their reasons for avoiding treatment. Most African Americans indicated they did not seek help because they thought the problem would get better $(22.9 \%)$ or it was not serious enough to seek help (22.9\%). Comparably, most
Caribbean Blacks (25.5 \%) indicated they did not seek help because the problem was not serious enough. When we explored variations by gender, we found no statistically significant differences in the reasons given for not seeking help. However, while only suggestive, most male respondents indicated they did not seek help because they believed their substance use problem would get better $(20.7 \%)$, while most female respondents indicated they did not seek help because they did not feel the problem was serious enough (27\%).

\section{Discussion}

The purpose of this study was to describe the ethnic and gender variations of help-seeking among African Americans and Caribbean Blacks. Our study found variation in use of service provider based on ethnicity and gender. Overall, we found most respondents obtained help from "other health care professionals," such as nurses and physician assistants, followed by informal sources of treatment, such as self-help groups like Alcoholics Anonymous or Narcotics Anonymous. Some gender differences were found in the use of health care professionals for substance use treatment, with men obtaining help from a psychiatrist more often than women. Factors associated with utilizing informal sources in this study were being African American, older, and having more education. Our findings are similar to previous NSAL findings on general service use for mental health disorders that found that African Americans were more likely to use informal help compared to Caribbean Blacks [22]. Other studies have found that Black substance users utilize self-help groups at higher rates, while additional reports indicate there is little difference 
Table 3 Reasons for avoiding treatment by ethnicity and gender among individuals who have not sought treatment for substance disorder problems: NSAL 2001-2003

\begin{tabular}{|c|c|c|c|c|c|c|c|c|c|c|}
\hline \multirow{3}{*}{$\begin{array}{l}\text { Reasons for delaying help-seeking for substance use } \\
\text { Treatment }\end{array}$} & \multicolumn{2}{|c|}{ African Americans } & \multicolumn{2}{|c|}{ Caribbean Blacks } & \multicolumn{2}{|c|}{ Male } & \multicolumn{2}{|c|}{ Female } & \multicolumn{2}{|c|}{ Total $N$} \\
\hline & \multicolumn{2}{|c|}{$(N=201)^{\mathrm{c}}$} & \multicolumn{2}{|c|}{$(N=47)^{\mathrm{c}}$} & \multicolumn{2}{|c|}{$(n=87)^{\mathrm{c}}$} & \multicolumn{2}{|c|}{$(n=161)^{\mathrm{c}}$} & \multicolumn{2}{|c|}{$(N=248)^{\mathrm{d}}$} \\
\hline & $n^{\mathrm{a}}$ & $(\%)^{\mathrm{b}}$ & $n^{\mathrm{a}}$ & $(\%)^{\mathrm{b}}$ & $n^{\mathrm{a}}$ & $(\%)$ & $n^{\mathrm{a}}$ & $(\%)^{\mathrm{b}}$ & $n^{\mathrm{d}}$ & $(\%)^{\mathrm{d}}$ \\
\hline Perceived problem got better/not serious & 100 & 49.8 & 20 & 42.6 & 37 & 42.5 & 83 & 51.6 & 120 & 48.0 \\
\hline Wanted to solve problem on my own & 33 & 16.4 & 10 & 21.3 & 14 & 16.1 & 29 & 0.18 & 43 & 17.0 \\
\hline No desire to seek formal help & 44 & 21.9 & 15 & 32.0 & 26 & 29.9 & 32 & 19.0 & 117 & 47.2 \\
\hline Unaware of treatment options or no resources (money, insurance, & 9 & 4.5 & 1 & 2.1 & 1 & 1.10 & 9 & 5.60 & 20 & 8.1 \\
\hline Cultural or religious reasons & 4 & 1.9 & 0 & 0 & 3 & 3.4 & 1 & 0.62 & 8 & 3.2 \\
\hline Sought out informal sources of help (friends, family, spirituality) & 5 & 2.5 & 2 & 4.2 & 4 & 4.6 & 3 & 1.80 & 14 & 5.6 \\
\hline
\end{tabular}

\footnotetext{
${ }^{a}$ Number of respondents who indicated this response was true for them

${ }^{\mathrm{b}}$ Percentage of respondents who indicated this response was true for them

${ }^{\mathrm{c}}$ The denominator for columns $\mathrm{b}$ is total $N$ per each column

${ }^{\mathrm{d}}$ Total $N$ represents the total number of respondents regardless of ethnicity or gender who indicated this response was true for them
}

in the frequency of utilization compared to other racial/ethnic groups, including non-Hispanic Whites [31-34]. Kaskutas and colleagues indicate that self-help groups might be more attractive to Black substance users because they are free and do not require insurance [32]. This is coupled with the fact that many Black substance users deal with mitigating financial difficulty, such as unemployment, when seeking treatment [12]. Other than insurance, we did not assess financial resources in relation to use of service providers for this paper. This would be an important factor to consider in future studies.

Some gender differences were found in the use of health care professionals for substance use treatment, with men obtaining help from a psychiatrist more often than women, however, overall, we found few differences in how Black males and females used services for substance disorder treatment. Our findings are in contrast to previous studies on gender and substance use help-seeking that found no differences in help-seeking by gender [35]. Our findings also differed from previous NSAL findings in which Caribbean Black women used fewer services than Caribbean Black men did [23]. In addition, a study by Neighbors and Howard found that overall, African American women were more likely to seek professional help than African American men and were more likely to utilize the services of a physician and social service agencies [36]. The type of referral source or even availability of treatment options may explain why males were more likely to receive help from a psychiatrist. This area needs further exploration and is beyond the scope of this paper.

We found that African American and Caribbean Black respondents who met criteria for a substance disorder problem, but postponed treatment, reported similar reasons for avoiding care. Respondents from both groups indicated they wanted to solve this problem on their own, while at the same time not recognizing their substance use issues as a problem that called for outside help. Respondents' reasons for avoiding treatment are similar to those of other racial/ethnic groups, as most people in need of treatment for substance use problems choose not to seek help. For example, Gant found that among a general sample of respondents diagnosed with an alcohol disorder, the majority avoided treatment because they either wanted to solve the problem on their own or believed it would get better [37]. Gant suggested that this attitude points to a lack of confidence in the alcohol treatment system, a finding comparable to those generated by the present study. Respondents overwhelmingly felt they could solve their substance use problems on their own. This is a consistent theme in substance use help-seeking literature and one that requires more attention in order to make treatment more accessible and acceptable [20, 37, 38]. It may be that Black men and women need additional information about the efficacy and utility of treatment for substance disorders before the disorders develop into severe and long lasting problems.

While our results indicated that respondents identified stigma around drug use and treatment as a relatively minor factor in avoiding treatment, we wonder if, in fact, the level of denial of having a problem and the denial about need for help might actually reveal hidden stigma. It may be that individuals who are either unaware or unwilling to admit they have a stigma about drug use and treatment may actually experience stigma and illustrate it by avoiding discussions about their feelings until problems become severe and care is sought. These results were found in responses from both males and females. Overall, male and female respondents felt their substance use problems did not warrant help or felt the 
problems would eventually improve. Contrary to previous studies that identified interpersonal obligations, transportation, and financial resources as major barriers that prevent women for entering treatment, few of our female respondents reported delaying treatment because of money or limited resources, or other problems such as childcare [39, 40].

\section{Limitations of the Study}

Despite the contributions that our study makes to scientific knowledge, there are limitations to consider when interpreting the findings. First, due to the question item oversight in the study questionnaire, neither alcohol dependence, without abuse, nor drug dependence, without abuse, was assessed. Therefore, the total number of respondents in the sample with substance disorders was smaller than it would have been otherwise. Respondents not included in the final sample could have had significant substance dependence problems. Second, due to the format of the questionnaire, we were unable to ascertain why individuals obtained help from a particular provider, or whether they were referred - or mandated - to see these providers. This level of inquiry would have led to a better understanding of the factors involved in the selection of the treatment providers. In addition, we cannot divulge the exact type of care received from their particular source of help, other than to estimate whether it was aligned with the general care one would receive from a certain profession based on their traditional services. Nor do we have information regarding the quality of care received by respondents from the various types of providers, or the efficacy of that care. We do not know, for example, if treatment provided by a physician, health professional, or mental health professional is better than or not as effective as what self-help groups or religious leaders provide. Finally, we were unable to assess information regarding respondents' tenure in treatment - whether there was completion of treatment or lack thereof. In the future, assessing referral source and the level, type, and quality of care administered would be helpful in understanding the patterns of help seeking within this population.

\section{Future Research}

There is still a great deal to uncover about the choices African Americans and Caribbean Blacks make when engaging or not engaging in the help-seeking process for substance disorder treatment. Our study has not fully uncovered the reasons why a substantial number of individuals do not seek care for substance disorder problems, nor has it explored whether there is a lack of parity in treatment effectiveness and quality of care. Our study does add to the growing knowledge of ethnic variation of substance use help-seeking patterns among Black Americans. With that, there are still lingering questions about help seeking that need to be answered in order to understand the complete treatment engagement process of Black Americans. These include how the selection of certain professionals and informal help for substance use treatment are mediated by the presence of co-occurring mental illness, healthrelated illnesses, involvement of the legal system, or even the role of nativity for Caribbean Blacks.

\section{Conclusions}

Substance disorder help-seeking literature is sparse in its investigation of patterns of service utilization among populations that make up Black America, particularly African Americans and Caribbean Blacks. Our findings uncovered few differences in ethnicity and gender variation concerning substance use help seeking. The absence of ethnic variation in the substance use help-seeking process has importance for future research efforts and treatment. Future studies on Black ethnic variation should take a closer look at problem severity, possible barriers to care, and referral source. These issues might be areas where variation exists and where it would most influence the treatment process (adequacy of care, access, duration). Longitudinal studies may be more efficient in capturing variation as they follow groups through a longer part of their substance use career. Knowing how ethnic variation is represented over time can help substance use practitioners meet potential unmet need in this population. Our study also found no significant ethnic variation in reasons for delaying substance disorder treatment. This tells us that African Americans and Caribbean Blacks may have similar views on the substance use help-seeking process or the need for treatment. Both groups cited their number one reason for avoidance was their problems were not serious enough for treatment. Individuals may not be aware that avoiding or delaying treatment is associated with a lengthier duration of substance disorder problems, which can have associated health and social consequences. This suggests it is useful to inform people that substance disorder treatment is worthwhile and should be sought before problems become severe. We were also able to deduce that many respondents who obtained treatment were involved with informal sources, such as selfhelp groups or human service professionals (including religious and spiritual leaders), which has implications for the availability of treatment, community resources, and financial resources related to treatment. This is a growing area of research, which requires greater empirical investigation. It is our intention that these results will contribute to the growing body of knowledge on help seeking and help to understand how to improve outreach and solve the problems of unmet need and treatment avoidance. 
Acknowledgments Dr. Redmond was supported through the following postdoctoral training grants from the National Institute on Drug Abuse training grant \#T32DA007267 and in part by National Institute of Mental Health training grant \#T32 MH16806-25. The content is solely the responsibility of the authors and does not necessarily represent the official views of the NIDA, NIMH, or NIH. The NSAL is supported by the National Institute of Mental Health (grant U01-MH57716) with supplemental support from the Office of Behavioral and Social Science Research at the National Institutes of Health and the University of Michigan.

Compliance with Ethical Standards The authors report no conflict of interest. The data used in this study represent secondary data analysis. Previous studies have reported on the informed consent procedures that were followed in the 191 collection of the data $[21,26]$.

\section{References}

1. Kessler RC, Demler O, Frank RG, Olfson M, Pincus HA, Walters EE, et al. Prevalence and treatment of mental disorders, 1990 to 2003. N Engl J Med. 2005;352:2515-23.

2. Wang PS, Lane M, Olfson M, Pincus HA, Wells KB, Kessler RC. Twelve-month use of mental health services in the United States. Arch Gen Psychiatry. 2005;62:629-40.

3. Substance Abuse and Mental Health Services Administration. Center for Behavioral Health Statistics and Quality. The NSDUH report: substance use and mental health estimates from the 2013 National Survey on drug use and health: Overview of Findings. Rockville, MD; 2014.

4. Alegria M, Canino G, Rios R, Vera M, Calderon J, Rusch D, et al. Inequalities in use of specialty mental health services among Latinos, African Americans, and non-Latino whites. Psychiatr Serv. 2002;53(12):1547-55.

5. Wells K, Klap R, Koike A, Sherbourne C. Ethnic disparities in unmet need for alcoholism, drug abuse, and mental health care. Am J Psychiatry. 2001;159(12):2027-32.

6. Substance Abuse and Mental Health Services Administration. Center of Behavioral Health Statistics and Quality. Need for and receipt of substance use treatment among blacks. Results from the National. Rockville, MD; 2013

7. Breslau J, Kendler KS, Su M, Aguilar-Gaxiola S, Kessler RC. Lifetime risk and persistence of psychiatric disorders across ethnic groups in the United States. Psychol Med. 2005;35:317-27.

8. Ojeda VD, McGuire TG. Gender and racial/ethnic differences in use of outpatient mental health and substance use services by depressed adults. Psychiatr Q. 2006;77(3):211-22.

9. Substance Abuse and Mental Health Services Administration, Office of Applied Studies. Results from the 2007 National Survey on Drug Use and Health: National Findings (NSDUH Series H-34, DHHS Publication No. SMA 08-4343). Rockville, MD; 2008.

10. Schmidt L, Greenfield T, Mulia N. Unequal treatment: racial and ethnic disparities in alcoholism treatment services. Alcohol Res. 2006;29(1):49-54.

11. Godette DC, Headen S, Ford CL. Windows of opportunity: fundamental concepts for understanding alcohol-related disparities experienced by young blacks in the United States. Prev Sci. 2006;7:31187.

12. Lee JA, Mavis BE, Stoffelmayr BE. A comparison of problems of life for blacks and whites entering substance use programs. J Psychoactive Drugs. 1991;23(3):233-9.

13. Woodward AT, Taylor RJ, Bullard KM, Neighbors HW, Chatters LM, Jackson JS. Use of professional and informal support by
African Americans and Caribbean blacks with mental disorders. Psychiatr Serv. 2008;59(11):1292-8.

14. Schmidt LA, Ye Y, Greenfield TK, Bond J. Ethnic disparities in clinical severity and services for alcohol problems: results from the National Alcohol Survey. Alcohol Clin Exp Res. 2007;31(1):4856.

15. Turner WL, Wallace B. African American substance use epidemiology, prevention, and treatment. Violence Against Women. 2003;9(5):576-89.

16. Hser Y-I, Maglione M, Polinsky ML, Anglin DM. Predicting drug treatment entry among treatment-seeking individuals. J Subst Abus Treat. 1998;3:213-20.

17. Milligan CO, Nich C, Carroll KM. Ethnic differences in substance abuse treatment retention, compliance, and outcome from two clinical trials. Psychiatr Serv. 2004;55(2):167-73.

18. Mojtabai R, Olfson M, Mechanic D. Perceived need and helpseeking in adults with mood, anxiety, or substance use disorders. Arch Gen Psychiatry. 2002;59(1):77-84.

19. Cheng TC, Robinson MA. Factors leading African American and black Caribbean to use social work services for treating mental and substance use disorders. Health Soc Work. 2013;38(2):99-109.

20. Perron BE, Alexander-Eitzman B, Watkins D, Taylor RJ, Baser R, Neighbors HW, Jackson JS. Ethnic differences in delays to treatment for substance use disorders: African Americans, black Caribbean and non-Hispanic whites. J Psychoactive Drugs. 2009;41(4):369-77.

21. Jackson JS, Neighbors HW, Torres M, Martin LA, Williams DR, Baser R. Use of mental health services and subjective satisfaction with treatment among black Caribbean immigrants: results from the National Survey of American life. Am J Public Health. 2007;97(1): 60-7.

22. Neighbors HW, Caldwell C, Williams DR, Nesse R, Taylor RJ, Bullard KM, et al. Race, ethnicity, and the use of services for mental disorders: results from the National Survey of American life. Arch Gen Psychiatry. 2007;64:485-94.

23. Woodward AT, Taylor RJ, Chatters LM. Use of professional and informal support by black men with mental disorders. Res Soc Work Pract. 2011;21:328-35.

24. Jackson JS, Torres M, Caldwell CH, Neighbors HW, Nesse RM, Taylor RJ, et al. National Survey of American life: a study of racial, ethnic and cultural influences on mental disorders and mental health. Int J Methods Psychiatr Res. 2004;13(4):196-207.

25. Colpe L, Merikangas K, Cuthbert B, Bourdon K. (National Institute of Mental Health). Guest editorial. Int J Methods Psychiatr Res. 2004;13:193-5.

26. Jackson JS, Neighbors HW, Nesse RM, Trierweiler SJ, Torres M. Methodological innovations in the National Survey of American life. Int J Methods Psychiatr Res. 2004;13:289-98.

27. WHO World Mental Health Survey Consortium. The prevalence, severity, and unmet need for treatment of mental disorders in the World Health Organization world mental health surveys. J Am Med Assoc. 2004;291:2581-90.

28. Kessler RC, Chiu WT, Demler O, Walters EE. Prevalence, severity and co-morbidity of 12-month DSM-IV disorders in the National Co-Morbidity Survey Replication (NCS-R). Arch Gen Psychiatry. 2005;62:617-27.

29. Kessler RC, Merikangas KR. The National Co-morbidity Survey Replication (NCS-R): background and aims. Int J Methods Psychiatr Res. 2004;13:60-8.

30. StataCorp. Stata Statistical Software (Release 9) [Computer software]. College Station, TX: StataCorp LP; 2005.

31. Humphreys K, Mavis B, Stofflemayr B. Factors predicting attendance at self-help groups after substance abuse treatment: preliminary findings. J Consult Clin Psychol. 1991;59(4):591-3. 
32. Kaskutas LA, Weisner C, Lee M, Humphreys K. Alcoholics anonymous affiliation at treatment intake among white and black Americans. J Stud Alcohol. 1999;60:810-6.

33. Tonigan JS, Connors GJ, Miller WR. Special populations in alcoholics anonymous. Alcohol Health Res World. 1998;22(4):281-5.

34. Flynn AM, Alvarez J, Jason LA, Olson BD, Ferrari JR, Davis MI. Chapter 10: African American Oxford house residents: sources of abstinent social networks. J Prev Interv Community. 2006;31(1-2): $111-9$.

35. Wu L, Ringwalt C. Use of substance abuse services by young uninsured American adults. Psychiatr Serv. 2005;56(8):946-53.
36. Neighbors HW, Howard CS. Sex differences in professional helpseeking among adult black Americans. Am J Community Psychol. 1987;15(4):403-17.

37. Grant BF. (1997). Barriers to alcoholism treatment: reasons for not seeking treatment in a general population sample. J Stud Alcohol. 1997;58:365-71.

38. Hingson R, Mangione T, Meyers A, Scotch N. Seeking help for drinking problems: a study in the Boston metropolitan area. J Stud Alcohol. 1982;43(3):273-88.

39. Allen K. Barriers to treatment for addicted African-American women. Journal of the National Medical Association. 1995;87:751-756.

40. Green CA. Gender and use of substance abuse treatment services. Alcohol Res Health. 2006;29(1):55-62. 